\title{
On the Effect of Environmental Exposure on Dwell Fatigue Performance of a Fine-Grained Nickel-Based Superalloy
}

\author{
S. PEDRAZZINI, D.J. CHILD, T. AARHOLT, C. BALL, M. DOWD, A. GIRLING, \\ H. COCKINGS, K. PERKINS, M.C. HARDY, H.J. STONE, and P.A.J. BAGOT
}

\begin{abstract}
The influence of sulfur contamination on the corrosion-fatigue behavior of a polycrystalline superalloy used in aero-engines is considered. Samples tested under a variety of environmental conditions (including exposures to air, $\mathrm{SO}_{x}$ gas, and salt) are characterized through a suite of high-resolution characterization methods, including transmission electron microscopy (TEM), secondary ion mass spectroscopy (nanoSIMS), and atom probe tomography (APT). The primary effect of sulfur contamination is to accelerate the crack growth rate by altering the failure mechanism. The SIMS and TEM analyses indicate Cr-Ti sulfide particle formation at grain boundaries ahead of and around oxidized cracks. The APT analysis suggests that these particles then oxidize as the crack propagates and are enveloped in chromia. The chromia is surrounded by a continuous layer of alumina within the cracks. All of the sulfur detected was confined within the particles, with no elemental segregation found at grain boundaries.
\end{abstract}

https://doi.org/10.1007/s11661-018-4752-7

(C) The Author(s) 2018

\section{INTRODUCTION}

SULFUR, as an impurity, typically has a significant, detrimental effect on the mechanical properties of nickel-based superalloys, particularly corrosion fatigue. ${ }^{[1-3]}$ Corrosion mechanisms are complex and vary with alloy composition, temperature, and loading regimes. They are broadly categorized into two main regimes: type I and type II. ${ }^{[4]}$ Type I hot corrosion occurs at elevated temperatures (generally $>800^{\circ} \mathrm{C}$ ) and is a result of molten salt deposits, while type II describes the attack of lower melting temperature eutectic salt mixtures that can exist in a stable liquid form around $600{ }^{\circ} \mathrm{C}$ to $750{ }^{\circ} \mathrm{C} .^{[5]}$ The increase in operating temperatures of aero-engine components,

S. PEDRAZZINI and H.J. STONE are with the Department of Materials Science and Metallurgy, University of Cambridge, 27 Charles Babbage Road, Cambridge CB3 0FS, UK. Contact e-mail: sp856@cam.ac.uk D.J. CHILD is with the Department of Materials, Loughborough University, Loughborough LE11 3TU, UK. T. AARHOLT is with the Department of Physics, University of Oslo, Postboks 1048, Blindern, 0316 Oslo, Norway. C. BALL and M. DOWD is with the Institute for Structural Materials, Swansea University, Bay Campus, Fabian Way, Swansea SA1 8EN, UK. A. GIRLING, H. COCKINGS and K. PERKINS are with the College of Engineering, Swansea University, Bay Campus, Fabian Way, Swansea SA1 8EN, UK. M.C. HARDY is with the Rolls-Royce plc, PO box 31 , Derby DE24 8BJ, UK. P.A.J. BAGOT is with the Department of Materials, University of Oxford, Parks Road, Oxford OX1 3PH, UK. Manuscript submitted April 5, 2018.

Article published online July 9, 2018 such as turbine discs, leads to conditions in which type II hot corrosion may be active. It is, therefore, essential to gain a deeper understanding of the mechanism involved and potential prevention routes. ${ }^{[5]}$

Previous work on type II hot corrosion of the turbine disc alloy RR1000 was performed by several authors. $^{[5-7]}$ Static, stress-free laboratory tests were performed by Encinas-Oropesa et al. ${ }^{[7]}$ on RR1000 exposed to $\mathrm{SO}_{x}$ gas. A thick dual-oxide layer was found to form, with an underlying chromium-sulfur-rich phase. Oxide spallation was enhanced by the sulfur exposure resulting in material loss and the attack progressed through wide, shallow pit formation. Corrosion-fatigue tests performed by Child et al. ${ }^{[5]}$ found that fatigue life can be greatly influenced by altering crack initiation behavior: shorter fatigue lives were obtained by increasing the initial salting level, which increases pitting rates. When sufficient load is applied, linear cracks form from the pits, while under lower loads, corrosion occurs through a mixed-oxide scale formation and spallation. ${ }^{[5]}$ Cockings et al. studied specifically the effect of local salt levels (flux) and stress levels during static or cyclic loading. ${ }^{[6]}$ They performed a systematic study, altering the salt levels and stress levels and found that the hot corrosion response of the alloy could deviate from the simplistic, traditional "double-bell" curve, highlighting the requirement for further specific studies characterizing crack tips to elucidate the failure mechanisms. ${ }^{[6]}$ 
However, several important aspects remain to be understood: How does the sulfur reside at the crack tips? How much sulfur contamination is necessary to cause embrittlement? Can sulfur be confined to specific phases through the targeted alloying addition of elements such as $\mathrm{Zr}$ and Hf? Both have long been added to the chemical compositions of nickel superalloys to act as sulfur getters, ${ }^{[8]}$ and some speculate the formation of $\mathrm{Hf}$-based $\mathrm{M}_{2} \mathrm{SC}$ sulfides. ${ }^{[8]}$ Others propose that the sulfides of $\mathrm{Hf}$ and $\mathrm{Zr}$ will have higher melting points compared to $\mathrm{Ni}$ sulfides, which wet grain boundaries at elevated temperatures, ${ }^{[9]}$ although the mechanism by which these elements could act as sulfur scavengers remains elusive.

In the present study, RR1000 was tested under dwell fatigue conditions at elevated temperature and exposed to air, $\mathrm{SO}_{x}$, and salt. High-resolution microstructural characterization was performed using transmission electron microscopy-energy-dispersive X-ray spectroscopy (TEM-EDX), secondary ion mass spectroscopy (nanoSIMS), and atom probe tomography (APT) to obtain accurate chemical maps of sulfur and oxygen containing phases at crack tips. This article represents the first instance of high-resolution characterization on this alloy after sulfur exposures and provides new insights on the role specific alloying elements play in the sulfidation and hot corrosion resistance of nickel superalloys.

\section{EXPERIMENTAL METHODS}

\section{A. Material}

The present work investigated a fine-grained (FG) variant of the polycrystalline turbine disc alloy RR1000 $(<10 \mu \mathrm{m}$ grain size). The composition of this alloy is given in Table I and was measured by inductively coupled plasma-optical emission spectrometry (ICP-OES).

The RR1000 alloy was produced through powder metallurgy methods comprising argon gas atomization, followed by sieving to obtain a distribution of powder sizes $<53 \mu \mathrm{m}$ in diameter. The powder was then compacted through hot isostatic pressing and subjected to both hot extrusion and isothermal forging, all of which were performed below the $\gamma^{\prime}$ solvus temperature. The as-forged samples were then heat treated through a combination of subsolvus solution annealing for 4 hours at $1120{ }^{\circ} \mathrm{C}$, then aging at $760{ }^{\circ} \mathrm{C}$ for 16 hours to yield a fine-grained microstructure and a trimodal distribution of $\gamma^{\prime}$ particles.

\section{B. Mechanical Testing}

Dwell fatigue samples were produced to the following specifications: $7 \times 7 \mathrm{~mm}$ square cross sections, threaded ends, gage length of $20 \mathrm{~mm}$, and corner $0.33-\mathrm{mm}$ notches were added at the midpoint of the gage length. Tests were conducted at $700{ }^{\circ} \mathrm{C}$, with $R=0$, with the stress applied following a trapezoidal waveform where the ramp up and ramp down were both set at 1 second and a 3600 seconds (1 hour) dwell at peak load was applied (overall waveform $t=1-3600-1-1$ seconds). The testing temperature was measured through use of two $n$-type thermocouples in contact with the center of the gauge length on either side of the notch. Samples were tested at a stress that is representative of operating conditions. Tests were performed under three environmental conditions:

1. sample tested in air,

2. air $+300 \mathrm{ppm} \mathrm{SO}_{x}$, and

3. air $+300 \mathrm{ppm} \mathrm{SO}_{x}+$ salt.

The salt used was in the form of a saturated solution of 98 pet $\mathrm{Na}_{2} \mathrm{SO}_{4}$ and 2 pct $\mathrm{NaCl}$ in a water/methanol mixture, which was applied to the notch using a micropipette following a previously established protocol. ${ }^{[6]}$ One sample was tested to failure under each experimental condition, and the fractured test pieces were used in the characterization study. All the characterization was performed on secondary cracks. (The samples were tested to failure; therefore, the primary crack was no longer available for analysis and one further test was performed and interrupted after fifteen 1-hour dwell cycles.) The primary crack was then analyzed and compared to secondary cracks to check the validity of the proposed mechanisms.

\section{Microstructural Characterization}

Samples of RR1000 were prepared for microstructural characterization by cutting and polishing to a 0.04 $\mu \mathrm{m}$ colloidal silica finish. They were then mounted onto Zeiss Al pin stubs with conductive silver paint. In the case of mechanically tested samples, the fracture surface was examined first, then cut, mounted side-on (with the notch in the left-hand corner), and polished to a $0.04 \mu \mathrm{m}$ colloidal silica finish. Scanning electron microscope (SEM) analysis of the fracture surfaces and polished samples was performed using either a Zeiss Merlin microscope with a Gemini II column or a Zeiss GeminiSEM 300 microscope. Both secondary and backscattered electron micrographs were acquired to fully exploit the capabilities for surface topography and channeling contrast ( $Z$ contrast). Samples used to analyze $\gamma^{\prime}$ distributions were electrolytically etched using a solution of $10 \mathrm{vol}$ pet orthophosphoric acid to dissolve the $\gamma$ matrix. Images obtained were then analyzed using Image J software to obtain $\gamma^{\prime}$ size distributions.

The EDX was performed with an Oxford Instruments XMAX system and processed using Aztec software. EDX maps were acquired at both 5 and $15 \mathrm{kV}$ to obtain

Table I. Chemical Composition of the Bulk Alloy Tested by ICP-OES

\begin{tabular}{lccccccccccccc}
\hline At. Pct & $\mathrm{Ni}$ & $\mathrm{Cr}$ & $\mathrm{Co}$ & $\mathrm{Mo}$ & $\mathrm{Al}$ & $\mathrm{Ti}$ & $\mathrm{Ta}$ & $\mathrm{C}$ & $\mathrm{B}$ & $\mathrm{Zr}$ & $\mathrm{Hf}$ & $\mathrm{S}$ \\
\hline FG RR1000 & bal & 16.5 & 18 & 3 & 6.4 & 4.3 & 0.6 & 0.13 & 0.08 & 0.04 & 0.5 & $<20 \mathrm{ppm}$ \\
\hline
\end{tabular}


good resolution of both light and heavy elements, and peaks were identified using the $\mathrm{K}$-lines for $\mathrm{Ni}, \mathrm{Cr}, \mathrm{Co}$, Al, Ti, O, S, C, and B and L-lines for Ta and Hf. Several major peak overlap issues were detected with the EDX data: the S K- $\alpha$ line overlaps with Mo L- $\alpha$, the B K- $\alpha$ line overlaps with Mo L- $\alpha$, the Cr L- $\alpha$ line overlaps with $\mathrm{O} \mathrm{K}-\alpha$, and finally the Ta and $\mathrm{Hf} \mathrm{L}-\alpha$ lines overlap. Ta, $\mathrm{Hf}$, Mo, and Cr, therefore, were only identified by their $\mathrm{K}-\alpha$ lines (which have no overlaps in the present work). However, in the case of the lighter elements $(\mathrm{O}, \mathrm{B}$, and $\mathrm{S})$, several steps had to be taken to ensure accuracy of the data. All peaks were fitted based on shape, size, and exact position using the Aztec TruMap algorithm. The algorithm proved sufficient to deconvolute overlapping peaks, though the validity of the fitting and deconvolution algorithm had to be proved by confirming the exact location of $\mathrm{S}, \mathrm{O}$, and $\mathrm{B}$ through NanoSIMS.

NanoSIMS analysis was performed using a Cameca NanoSIMS 50. The side-cut samples of the fracture surfaces, which had been mechanically polished for SEM analysis, were used. A $16 \mathrm{keV} \mathrm{Cs}^{+}$primary ion beam was used for ion sputtering from the sample surface. Beam currents of 1.6 to $1.9 \mathrm{pA}$ were used for the measurements. Prior to each measurement, the sample surface was charged with a higher current (6 to $10 \mathrm{nA}$ ) to implant $\mathrm{Cs}^{+}$ions and achieve a higher yield. The instrument was aligned to detect the following ionic species: ${ }^{12} \mathrm{C}^{-},{ }^{16} \mathrm{O}^{-},{ }^{32} \mathrm{~S}^{-}$, and ${ }^{35} \mathrm{Cl}^{-}$. Image processing was carried out using Image $J$ software [U.S. National Institutes of Health (Bethesda, MD)] and the OpenMIMS plugin [National Resource for Imaging Mass Spectrometry (Harvard University, Cambridge, MA)].

EBSD was performed around the crack tips using a

*JEOL is a trademark of Japan Electron Optics Ltd., Tokyo.

JEOL* 6500F field emission gun SEM with an Oxford Instruments detector and analyzed using TSL-OIM software. Samples were tilted at $70 \mathrm{deg}$ and a working distance of $15 \mathrm{~mm}$ was used. The microscope was operated at $30 \mathrm{kV}$ with a $13 \mathrm{nA}$ beam current and with a step size of $50 \mathrm{~nm}$.

Samples for TEM were prepared using a FEI Helios dual-beam SEM-focused ion beam (FIB). Samples were protected through the application of an in situ deposited platinum layer; then trenches were dug and a lamella was extracted using an Omniprobe micromanipulator. Samples were then thinned to electron transparency at $30 \mathrm{kV}$. To image and characterize the samples, a Technai Osiris microscope, equipped with an XMAX**

\footnotetext{
**XMAX is a trademark of Oxford Instruments, Abingdon, United Kingdom.
}

windowless energy-dispersive X-ray detector, was used. The microscope was operated at $200 \mathrm{kV}$, and EDX spectra were collected between 0 and $10 \mathrm{kV}$.

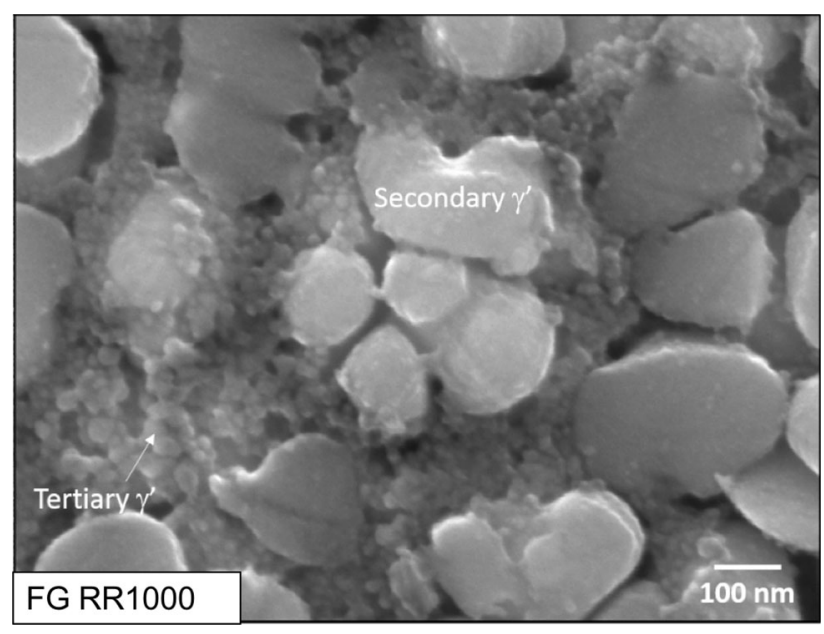

Fig. 1-Secondary electron micrograph of the etched sample (whereby the $\gamma$ matrix was dissolved) showing the distribution of secondary and tertiary $\gamma^{\prime}$ particles.

Samples for APT were made using a FIB site-specific lift-out technique. A Zeiss NVision 40 dual-beam SEM-FIB was used along with a Kleindiek micromanipulator. Samples were mounted on standard Cameca $\mathrm{Si}$ microtip coupons and sharpened until the apex was $<100 \mathrm{~nm}$ in diameter. Samples were imaged during every step of preparation using the built-in InLens detector at $5 \mathrm{kV}$. A LEAP $3000 \mathrm{X}$ HR was used for analysis, with laser energy of $0.4 \mathrm{~nJ}$, frequency of 160 $\mathrm{kHz}$, evaporation rate of 0.7 , and temperature of -223 ${ }^{\circ} \mathrm{C}$.

\section{RESULTS}

\section{A. Microstructural Characterization of Untested RR1000 Alloy Samples}

Figure 1 shows an SEM micrograph performed on the etched sample with the purpose of revealing the $\gamma^{\prime}$ distributions. A bimodal distribution of spheroidal, large secondary $\gamma^{\prime}$ particles is shown, surrounded by tertiary $\gamma^{\prime}$ particles. Secondary $\gamma^{\prime}$ particles had a mean planar diameter between 250 and $350 \mathrm{~nm}$ and tertiaries between 7 and $50 \mathrm{~nm}$.

The grain boundary character and grain boundary serrations were analyzed through backscattered electron imaging on the unetched sample, and SEM micrographs and associated EDX maps are shown in Figure 2. The planar grain boundaries shown in Figure 2(a) were characterized in this same sample as part of a previous study and were found by APT to be enriched in Mo and $\mathrm{B}$ in solid solution. ${ }^{[10]}$ These were the main, representative examples of grain boundary morphology present in the sample. In some rare occurrences, grain boundary serrations were observed and associated with the presence of localized, ellipsoidal $<20-\mathrm{nm}$ wide and 100- to 200-nm-long Mo-Cr borides, an example of which is shown in Figure 2(b). Few such examples were 

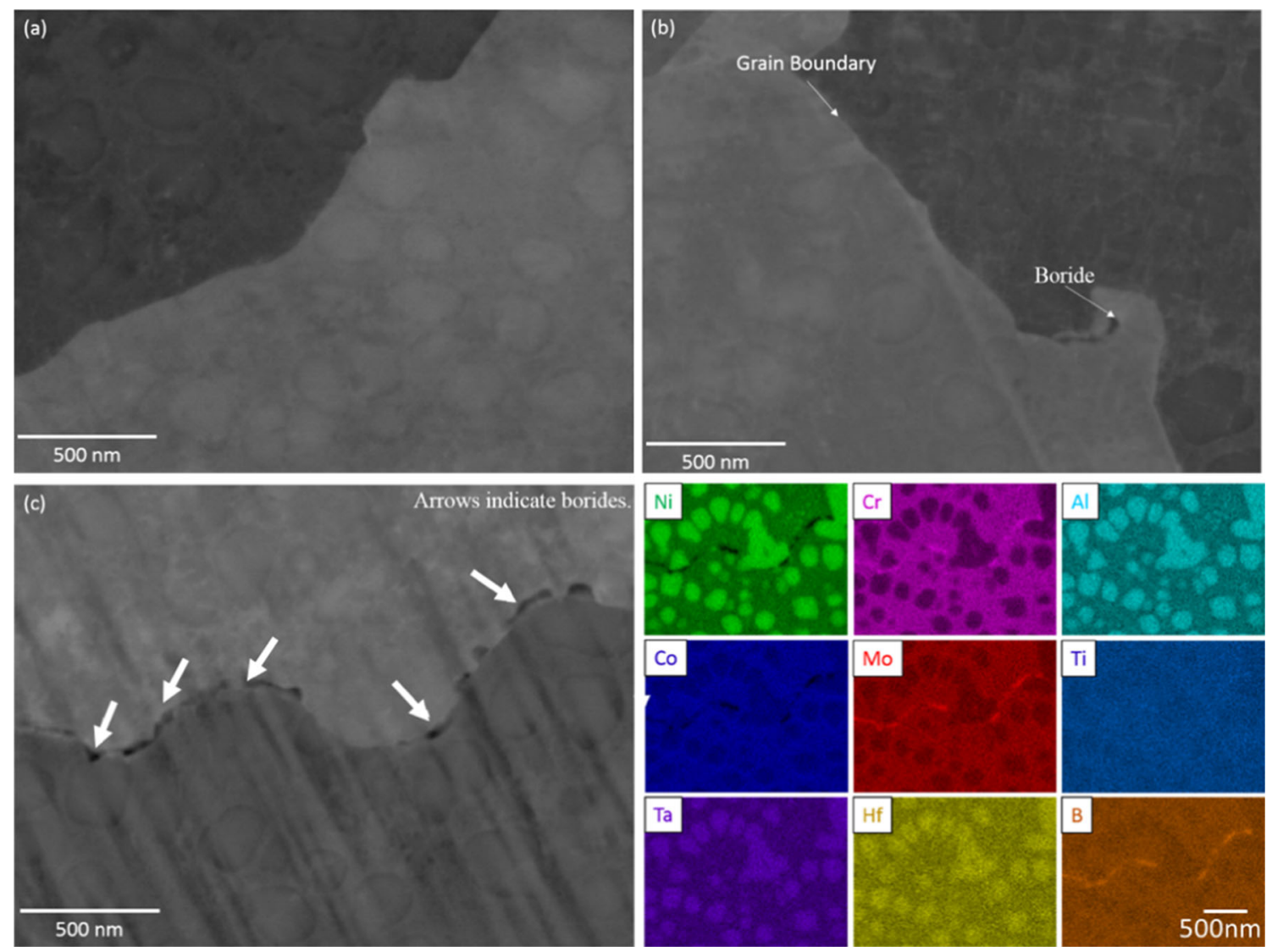

Fig. 2-SEM backscattered electron images of the unetched sample showing (a) a planar grain boundary that is precipitate free and representative of the majority of grain boundaries in the sample, $(b)$ a rare grain boundary boride accompanied by a serration, and $(c)$ the only grain boundary found in the sample that was fully serrated and decorated with Mo-Cr-borides with the accompanying EDX maps.

observed within the sample. One exceptional case was found, in which a grain boundary decorated with a semicontinuous series of borides exhibited a fully serrated morphology, with serrations of amplitude $\sim 500 \mathrm{~nm}$. Two current separate investigations were carried out on the effect of boron on grain boundary character, ${ }^{[1]}$ grain boundary serrations, ${ }^{[12]}$ and their role in improving ductility and creep lifetime in a polycrystalline nickel-based superalloy, which is beyond the scope of the present work. For the present investigation, it is important to note that prior to mechanical testing and thermal exposure to $700{ }^{\circ} \mathrm{C}$, most grain boundaries were planar, enriched in Mo and B in solid solution, and precipitate free, with a few rare exceptions in which Mo-Cr borides were observed. The occasional presence of Ta-rich MC carbides and larger intragranular Mo-Cr borides was also observed in this sample and documented in a previous characterization study, where the borides were shown by APT to be of $\mathrm{M}_{5} \mathrm{~B}_{3}$ type. ${ }^{[10]}$

\section{B. Failure Mechanism Investigation}

Despite a limited database that precluded any repeat tests, the addition of $300 \mathrm{ppm} \mathrm{SO}_{x}$ gas to the testing atmosphere appears to have accelerated crack growth when compared to air exposure. The crack growth rates measured as a function of stress intensity during the dwell fatigue tests for the four samples studied are summarized in Table II.

SEM micrographs of the fracture surfaces of each of the test samples, which were tested to failure, are shown in Figure 3. Samples 1 and 2 (air and air $+300 \mathrm{ppm}$ $\mathrm{SO}_{x}$ ), shown in Figures 3(a) and (b), failed at $90 \mathrm{deg}$ from the tensile axis in a uniaxial tensile mode. Fracture appears intergranular in all samples. The fact that crack growth in air is intergranular (in RR1000 dwell fatigue samples tested at $750{ }^{\circ} \mathrm{C}$ ) was also previously observed by Li et al. ${ }^{[13]}$ Sample 3, which was exposed to salt, is different, however. The fracture surface, shown in the secondary electron micrograph in Figure 3(c) and in the backscattered electron micrograph in Figure 3(d), is also at $90 \mathrm{deg}$ from the tensile axis. These images show evidence of internal cracking and oxidation/corrosion effects. The secondary electron image shown in Figure 3(c) shows internal cracks extending approximately $300 \mu \mathrm{m}$ below the surface that are decorated by cavities and block-shaped phases. These phases are revealed by the backscattered electron image in Figure 3(d), appearing darker than the matrix; therefore, they are made of lighter elements, possibly oxides. Internal cracks can also be observed in this micrograph, extending at $45 \mathrm{deg}$ from the fracture surface.

Figure 4 shows an enlarged view of one of the internally oxidized cracks and its corresponding EDX map. In Figure 4, a backscattered electron micrograph 
Table II. Dwell Fatigue Crack Growth Rate Data Collected for the Four Prenotched RR1000 Samples Exposed to Air and Air + 300 ppm SO $\mathrm{SO}_{x}$ and Air +300 ppm SO $\mathrm{SO}_{x}$ Salt; All Samples were Tested to Failure, Unless Otherwise Indicated

\begin{tabular}{lllll}
\hline Sample Number & Waveform & \multicolumn{1}{c}{ Environment } & $\Delta K\left(\mathrm{MN} \mathrm{m}{ }^{-3 / 2}\right)$ & $\mathrm{d} a / \mathrm{d} N(\mathrm{~m} / \mathrm{cycle})$ \\
\hline 1 & $1-3600-1-1$ & air & 40 & $1.1 \times 10^{-4}$ \\
2 & $1-3600-1-1$ & air $+300 \mathrm{ppm} \mathrm{SO}_{x}$ & 40 & $5.0 \times 10^{-4}$ \\
3 & $1-3600-1-1$ & air $+300 \mathrm{ppm} \mathrm{SO}_{x}+$ salt & $($ estimated $) 45$ & $1.0 \times 10^{-3}$ \\
4 & $1-3600-1-1$ & air $+300 \mathrm{ppm} \mathrm{SO}_{x}+$ salt & 40 & $6.0 \times 10^{-4}$ \\
& & (interrupted after 15 cycles) & \\
\hline
\end{tabular}

It is worth highlighting that these are first results based on single tests, so further testing is required to obtain statistical errors.
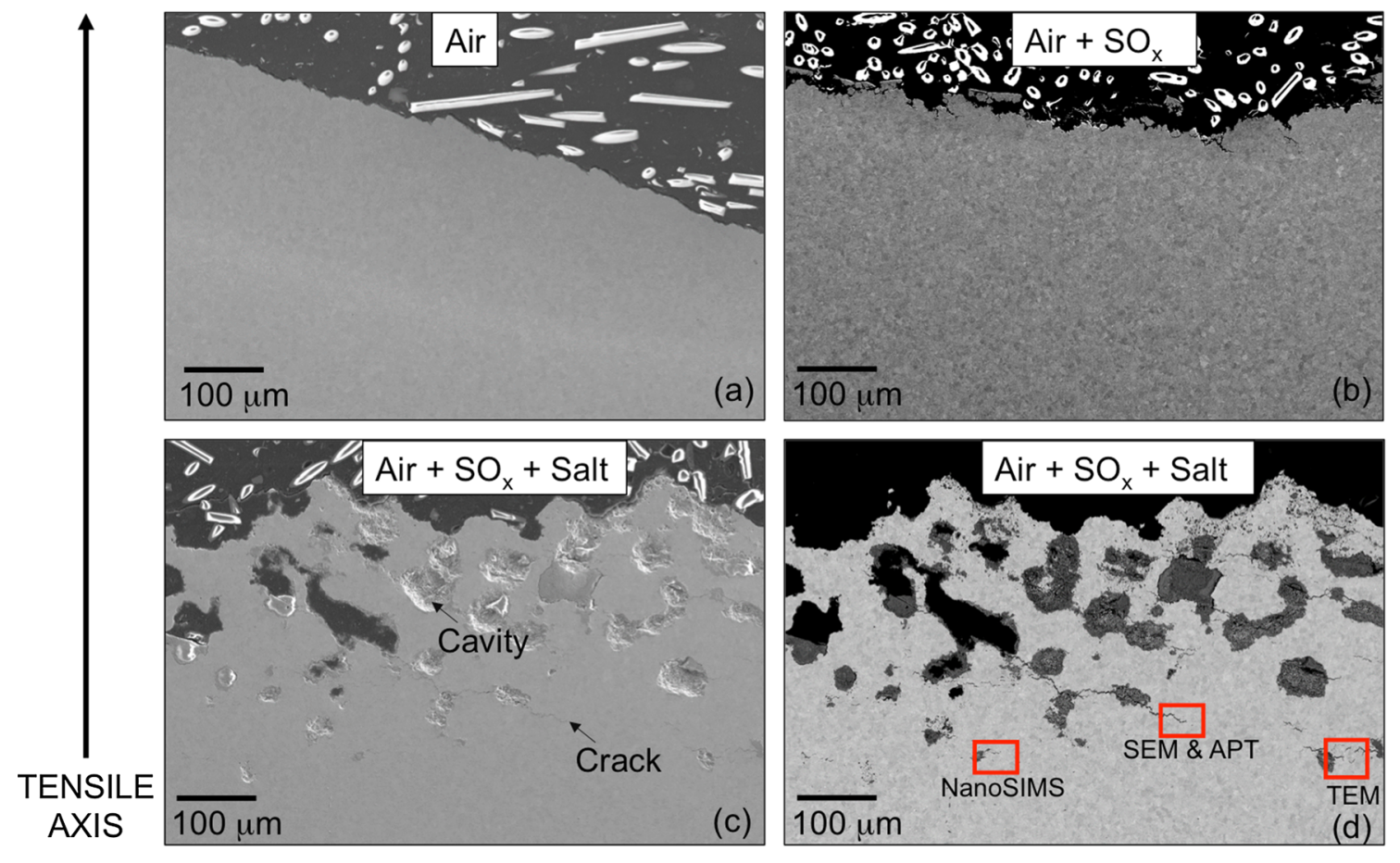

Fig. 3-SEM secondary electron micrographs of the fracture surfaces of dwell fatigue samples exposed to $(a)$ air, $(b)$ air +300 ppm $\mathrm{SO}_{x}$, and (c) air +300 ppm $\mathrm{SO}_{x}+$ salt. (d) Backscattered electron micrograph of the sample shown in (c). The exact locations of the cracks analyzed using APT, TEM, and NanoSIMS in Figs. 4 through 10 are highlighted by the red boxes (Color figure online).

illustrates the oxidized region around and within the crack tip as well as the presence of secondary crack tips. These are likely to be connected to the main crack beneath the surface. The EDX maps in Figure 4 show that the large cavity and the crack tip that extends from it are enriched in chromium, which suggests the presence of chromia.

Due to the difficulties encountered when attempting to identify the location of lighter elements, such as S, O, C, and $\mathrm{Cl}$, by EDX, NanoSIMS analysis was performed, the results of which are shown in Figure 5. The carbon map indicates the presence of carbides, which are distributed along the crack path and intragranularly within adjacent grains. These are likely to be the MC carbides also shown in Figure 6. Oxygen was identified by the peak at $16 \mathrm{amu}$ and is found inside the crack. Sulfur is at $32 \mathrm{amu}$, which could have overlapped with $\mathrm{O}_{2}$, but the mass resolution of the nanoSIMS was sufficient to detect two peaks at 31.82 and $31.84 \mathrm{amu}$, one of which overlapped with the peak at 16 (oxygen) and one which did not (sulfur). Sulfur was detected in distinct particles ahead of and around the crack tip. Chlorine is identified by the peak at $35 \mathrm{amu}$. The sulfur, therefore, was confirmed to segregate to specific particles ahead of and around the crack tip, and not within the oxide. Chlorine (also introduced in as contamination due to the exposure to salt, though only as 2 pct of the solution) was, unlike sulfur, detected within the crack. NanoSIMS is an unsuitable technique for the analysis of heavier metallic ions due to its ability to detect only ions that can be charged negatively and the limitation of characterizing a maximum of five elements at a time.

Figure 6(a) shows a close-up backscattered electron micrograph of the crack tip, which gives an insight into the type of oxides present within. In the EDX maps shown in Figure 6(b), the end of the crack appears to contain a $\mathrm{Cr}$-Ti-rich oxide, most likely a form of rutile 

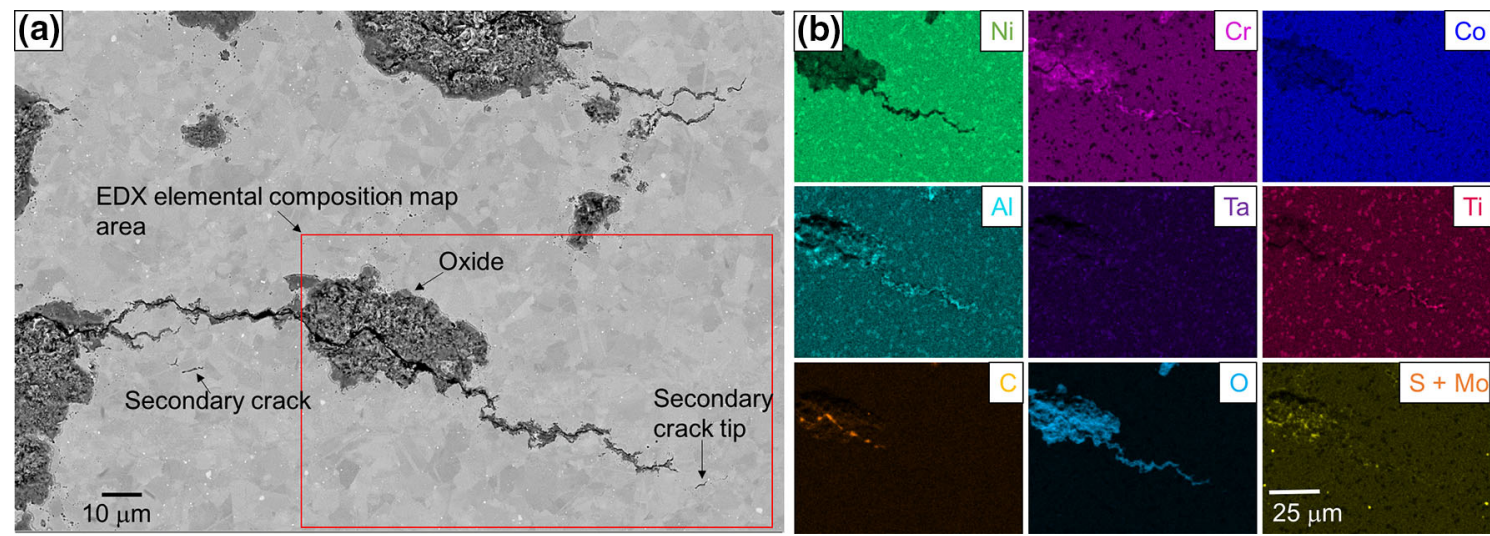

Fig. 4-(a) SEM backscattered micrograph from the region labeled "SEM and APT" in Fig. 3 and (b) EDX elemental composition maps from the area highlighted in red, showing the $\mathrm{K}$ lines for each element. Molybdenum and sulfur are plotted on the same map due to peak overlaps (Color figure online).
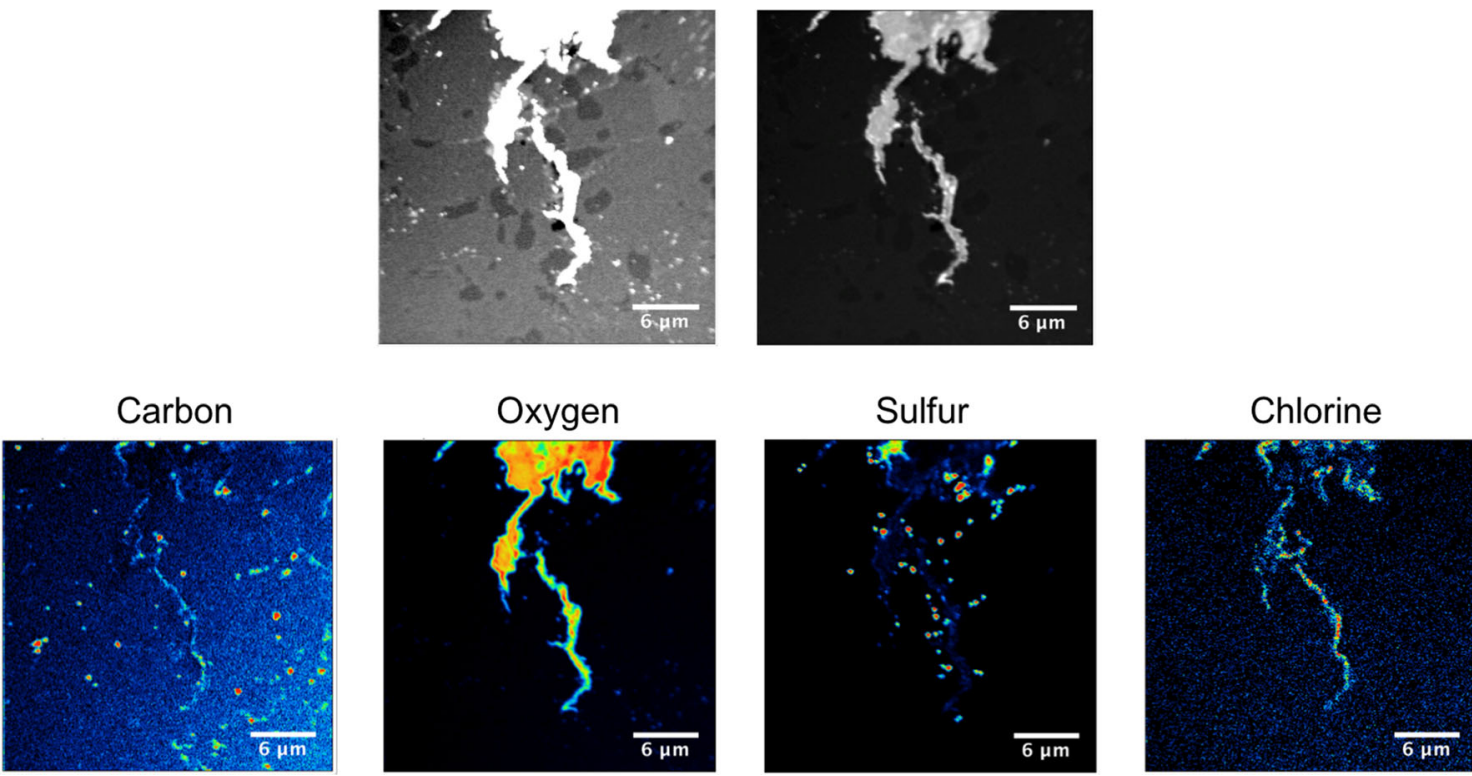

Fig. 5-Secondary electron micrographs (top) with different contrast to show different phases around the crack and within the oxide, and element concentration maps determined using NanoSIMS (bottom) showing the $\mathrm{C}, \mathrm{O}, \mathrm{S}$, and $\mathrm{Cl}$ locations within and around the crack tips.

$(\mathrm{Ti}, \mathrm{Cr}) \mathrm{O}_{2}$. The outer edges of the rutile are covered by what appears to be a continuous thin film of alumina, which also decorates the secondary crack tip. The main and secondary crack tips and the grain boundaries ahead of the crack tip are decorated with darker particles, which, based on the salt exposure of the sample and the NanoSIMS results shown in Figure 5, may be borides, sulfides, or other grain boundary precipitates. The evidence of the intergranular nature of both the cracking and of the sulfur-rich particles is given by the EBSD in Figure 6(c). In generating Figure 6(c), a filter was applied to the resulting map removing the areas in which the confidence index was less than 20 pct. High-angle grain boundaries (> $15 \mathrm{deg}$ ) are shown in black.

Previous studies have shown that oxides, formed on nickel superalloys, can contain further nanoscale segregation, which would be beyond the resolution of the
EDX. ${ }^{[14,15]}$ As such, site-specific atom probe needles were prepared from the same crack tip shown in Figures 4 and 6 . The procedure for sample preparation and the exact locations the atom probe needles were extracted from are shown in Figure 7. Figure 7(a) is the same crack shown in Figure 6(a) but highlights the area selected for atom probe analysis and (in red) the location of the needles. Figures 7(b) through (f) are secondary electron micrographs that show step-by-step sample preparation. First, location markers were deposited (Figure 7(b)); then, trenches were dug around the selected area to create a microcantilever beam (Figure 7(c)). The cantilever was subsequently extracted using a manipulator (Figure 7(d)), and sections of it were welded onto Cameca silicon flat-top coupons using FIB-deposited W (Figure 7(e)). Figure 7(f) is a side view of the sample and the silicon coupon before the sample was sharpened. 


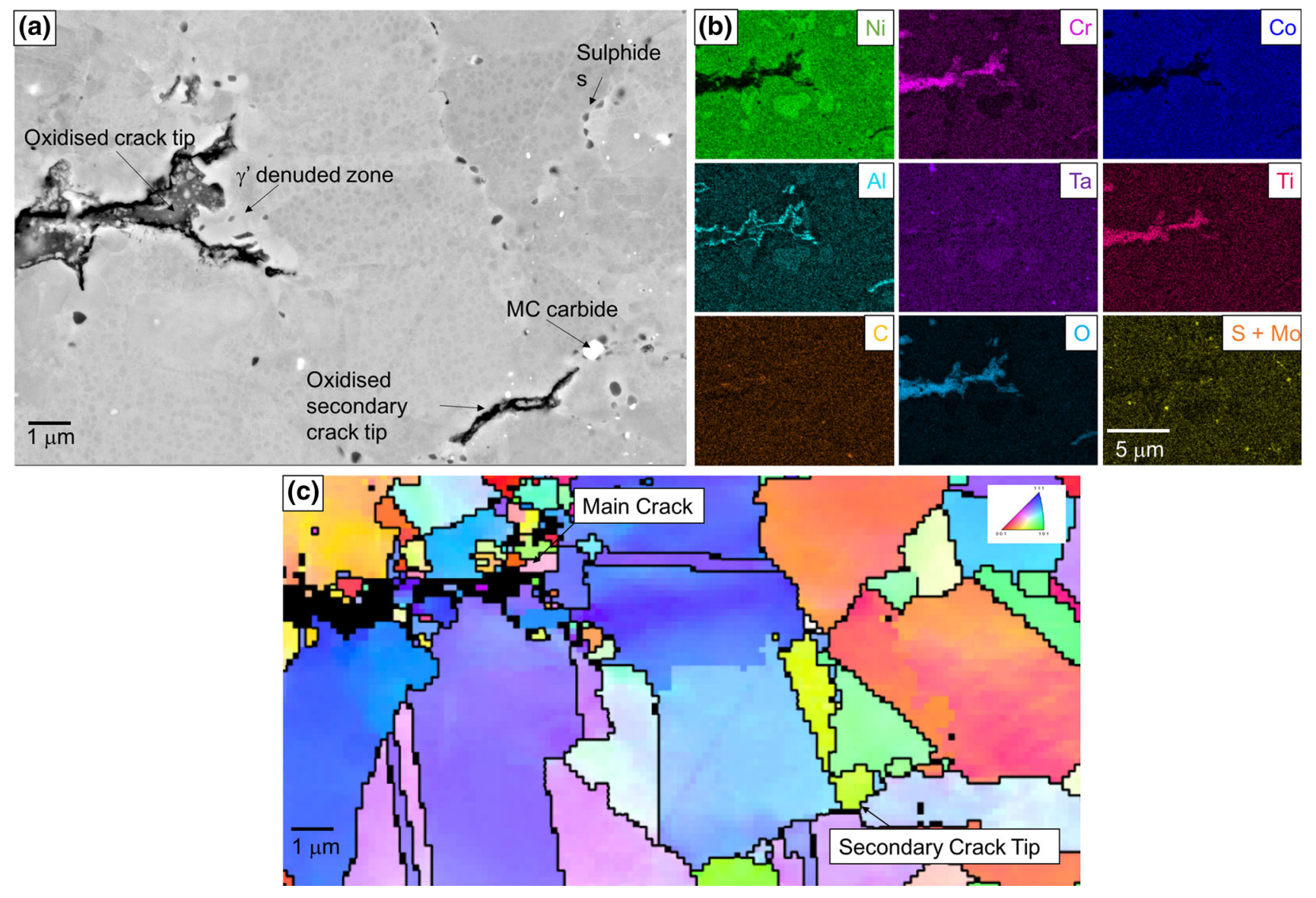

Fig. 6- (a) SEM backscattered micrograph showing a closeup of the crack tip, (b) EBSD map of the same region showing the intergranular nature of the crack and some of the particles, and (c) EDX elemental concentration maps for each element.

Atom probe needle 1, as shown in Figure 7(a), was taken from the oxidized region of the crack approximately $3 \mu \mathrm{m}$ away from the tip. SEM micrographs of the needle during sharpening are shown in Figures 8(a) and (b).

The EDX map in Figure 6 shows that the crack is filled with a region enriched in $\mathrm{Cr}, \mathrm{Ti}$, and $\mathrm{O}$. Based on EDX measurements alone, this phase could have been mistaken for rutile. However, Figure 8(c) shows an atom probe reconstruction from the oxidized region of the crack tip, whereby the needle itself is made up of several different types of oxides, including spinel $\mathrm{NiCr}_{2} \mathrm{O}_{4}$, chromia, rutile, and small amounts of unoxidized, Cr-depleted $\gamma$ phase. It is interesting to note the presence of $\mathrm{Ti}$ in both the $\mathrm{NiCr}_{2} \mathrm{O}_{4}$ spinel and in the rutile and its complete absence from the chromia.

The atom probe needle shown in Figure 9 (needle 2) was located in a position specifically targeted to incorporate the tip of the oxidized crack and a part of the grain boundary ahead of it, as shown in Figure 7(a). The surrounding material was milled until the grain boundary ahead of the oxidized region was visible, along with a line of particles ahead of it. The needle in the last stages of sharpening is shown in Figures 9(a) and (b). Figure 9(c) is a reconstruction of the needle. The reconstruction shows (on the right) a grain boundary enriched in Mo, O, and C. Grain boundaries in RR1000 are known to be enriched in molybdenum and carbon (or boron). ${ }^{[10]}$ Oxygen was also detected at the grain boundary. However, no evidence of sulfur was found in this location. A maximum concentration of up to 20 at. pet $\mathrm{O}$ was detected at the grain boundary directly ahead of the crack tip, proving oxygen enrichment. This concentration is not enough to be considered an oxide. A one-dimensional (1-D) concentration profile across the arrow shown in Figure 9(c) provides quantitative data on the local elemental concentrations.

The third atom probe needle, whose location is also shown in Figure 7(a), contains unoxidized secondary and tertiary $\gamma^{\prime}$ particles and is shown in Figure 10. The needle was taken approximately $5 \mu \mathrm{m}$ ahead of the crack tip. Figures 10(a) and (b) show the final stages of sharpening. Figure 10(a), in particular, shows a uniform distribution of $\gamma^{\prime}$ particles within the $\gamma$ matrix. Figure $10(\mathrm{c})$ is a reconstruction, where the individual phases are marked and shown with distinctive elemental maps. The interfaces are isoconcentration surfaces at 12 at. pct Cr. Table III contains the elemental compositions of secondary and tertiary $\gamma^{\prime}$ phases and of the $\gamma$ matrix that were obtained from the reconstruction in Figure 10(c). 

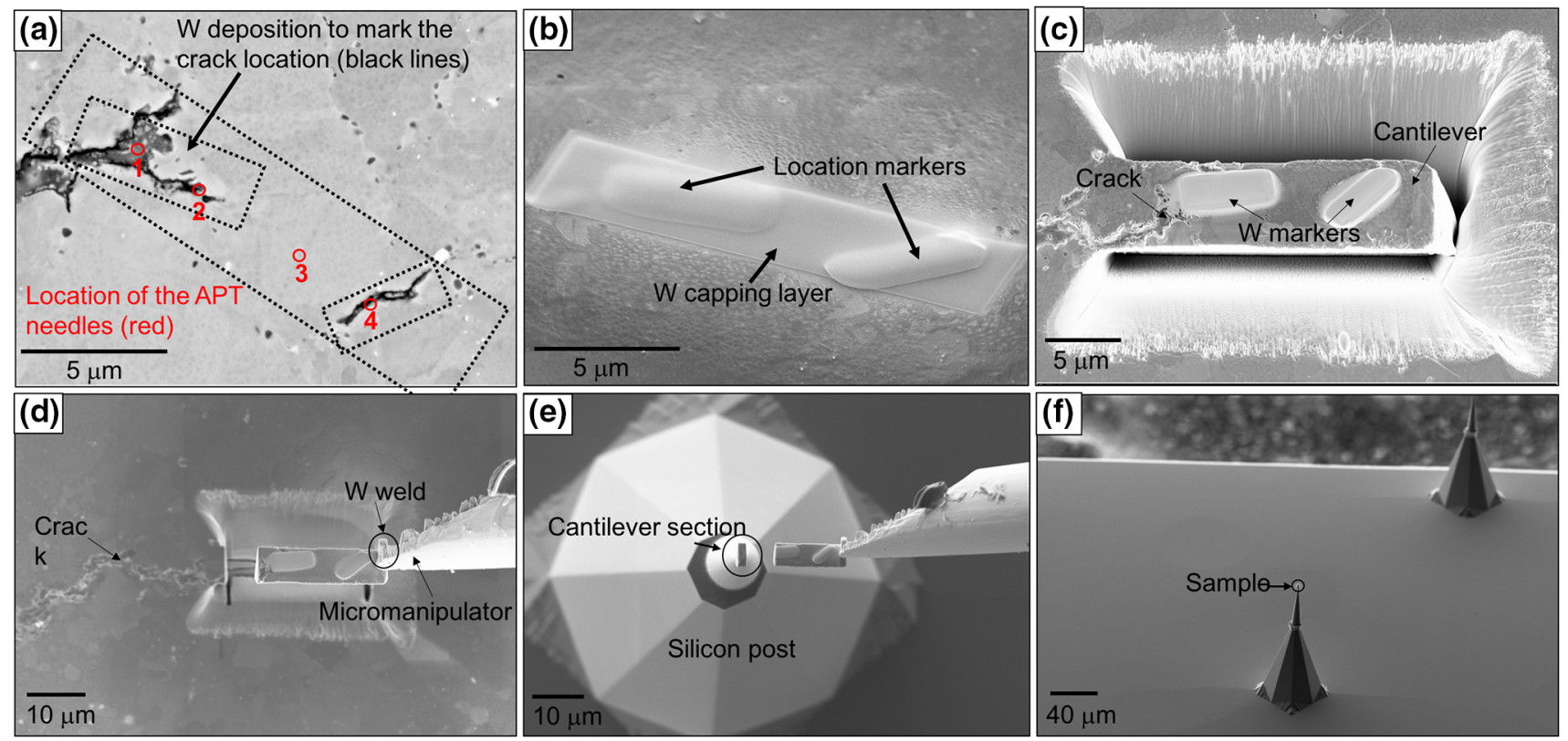

Fig. 7-(a) SEM backscattered electron micrograph showing the location of the samples analyzed using APT. The step-by-step sample preparation is shown with secondary electron micrographs, with $(b)$ showing the tilting and deposition of W markers and a protective capping layer to minimize $\mathrm{Ga}$ implantation. (c) The milling of the cantilever beam around the crack tip, (d) the lift-out process using a micromanipulator, $(e)$ a top view of the samples being welded onto a standard silicon Cameca flat-top coupon, and $(f)$ a side view, showing the silicon post the samples are mounted on.

A fourth atom probe needle was extracted from the tip of the secondary crack, as identified in Figure 7(a). The oxide-metal interface was targeted, and it was acquired from a region that contains a $\gamma^{\prime}$ precipitate being oxidized. The sample in two stages of sharpening and the resultant APT data are shown in Figure 11. The composition of the $\gamma^{\prime}$ at the transition point showed an oxygen gradient and an Al- and Ti-depleted zone ahead of the oxidizing interface. Silicon was seen to segregate to the alumina, while carbon was rejected ahead of the oxide-metal interface. No evidence of $\mathrm{S}$ was observed. The lack of sulfur is noteworthy, as it is consistent with the nanoSIMS results and shows that sulfur diffused through the grain boundary, though it all appears to be contained within well-defined particles and not present as elemental segregation at the crack tip or at the oxide-metal interface.

Figure 12 shows a bright-field TEM micrograph of the oxidized crack tip, taken from the region shown in Figure 3(d). Some of the grain boundaries around the crack tip contain particles that were analyzed using scanning transmission electron microscopy (STEM)-EDX, which are also shown in Figure 12. The EDX compositional maps elucidate the formation of $\mathrm{Ti}-\mathrm{Cr}$ sulfides ahead of and around the crack tip, as well as the occurrence of Ta-Hf- $\mathrm{Zr}$ oxide particles. This provides further evidence to indicate that grain boundary precipitates, such as the ones around the crack in Figure 6, are, in fact, sulfides. The lack of association between the $\mathrm{S}, \mathrm{C}, \mathrm{Hf}$, and $\mathrm{Zr}$ suggests that the latter two elements are not acting as sulfur scavengers by forming $\mathrm{M}_{2} \mathrm{SC}$ sulfides.

\section{Primary Crack Tip Characterization}

An interrupted dwell fatigue test was performed (sample 4) in order to compare the crack propagation mechanism of the primary and secondary cracks. Secondary cracks were analyzed in the present work because the specimens were tested to failure; therefore, the primary crack was no longer present. However, secondary cracks could have been stationary for a substantial portion of the test, therefore having undergone a different environmental and thermal exposure when compared to the primary crack. To ensure the mechanisms described previously while characterizing secondary cracks were representative, the primary crack tip of an interrupted test was used for comparison. Backscattered electron images of the primary crack are shown in Figure 13.

Figure 13(a) shows the entire crack and the locations in which the EDX maps shown in Figures 13(b) and (c) were acquired. Figure 13(b) provides a backscattered electron micrograph and associated EDX compositional maps showing a portion of the crack that appears very similar to the secondary crack observed in Figure 6. In the EDX maps shown, we can observe the internal oxide made primarily of chromia-rutile and surrounded by a continuous layer of alumina. Also visible are the Cr-Ti sulfides 


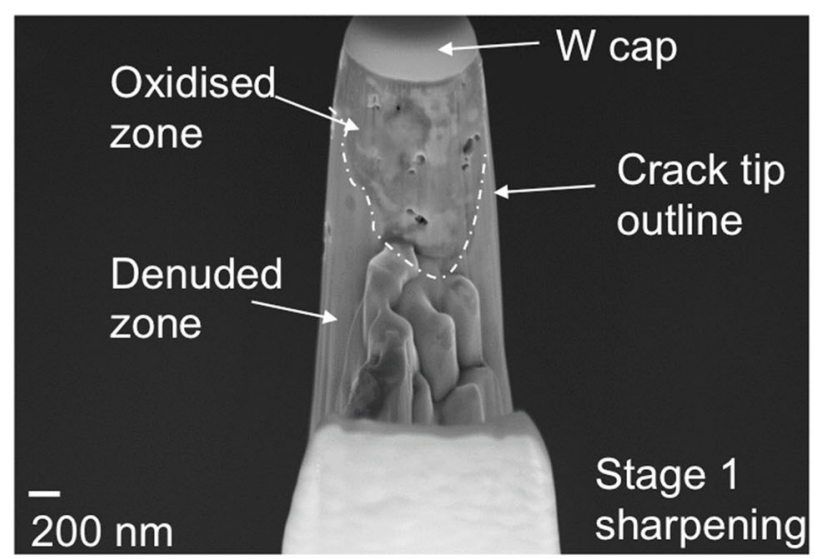

(a)

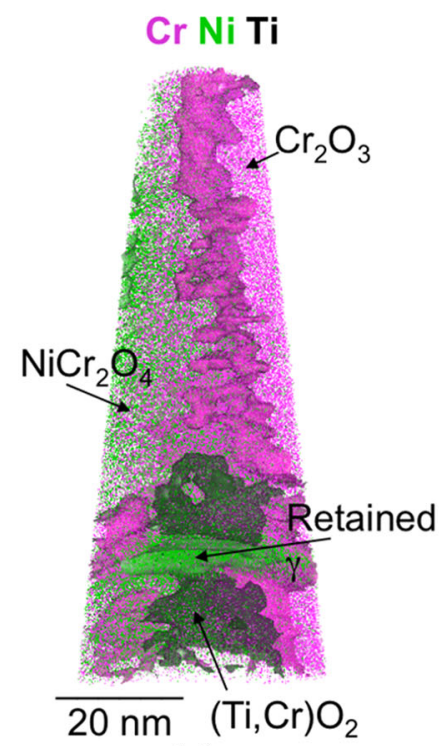

(c)

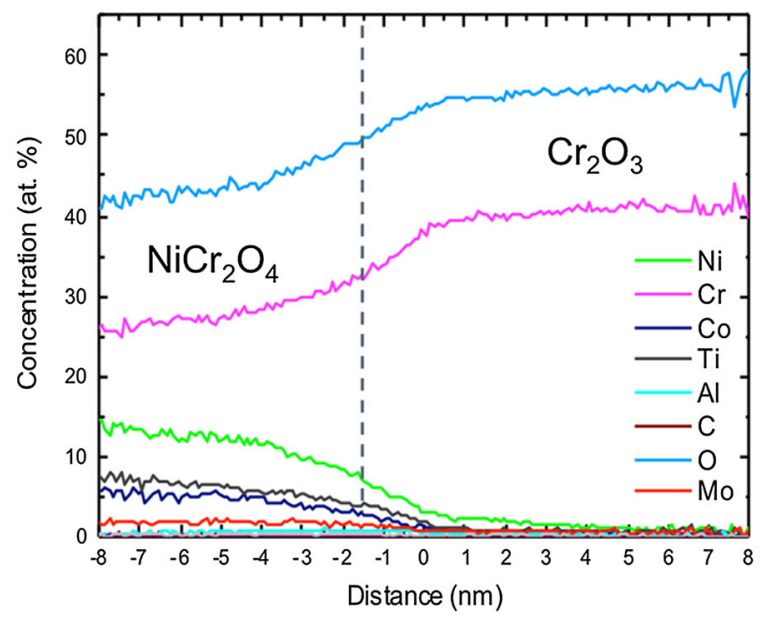

(e)

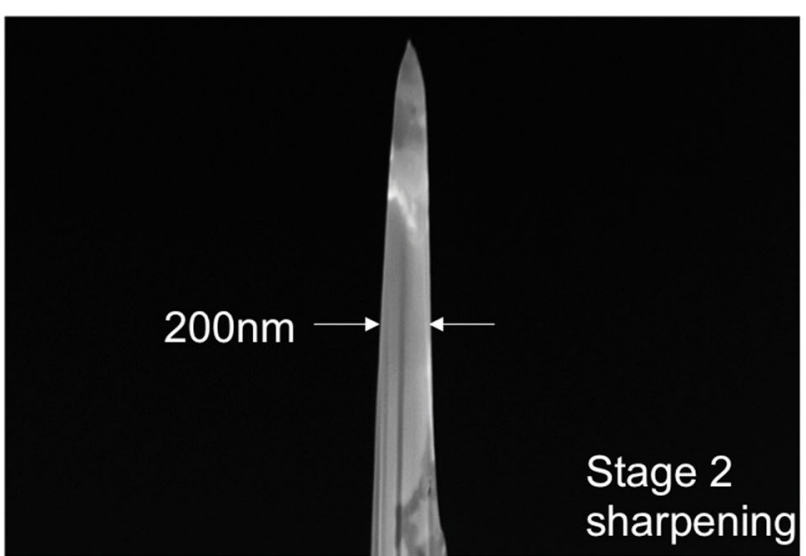

(b)

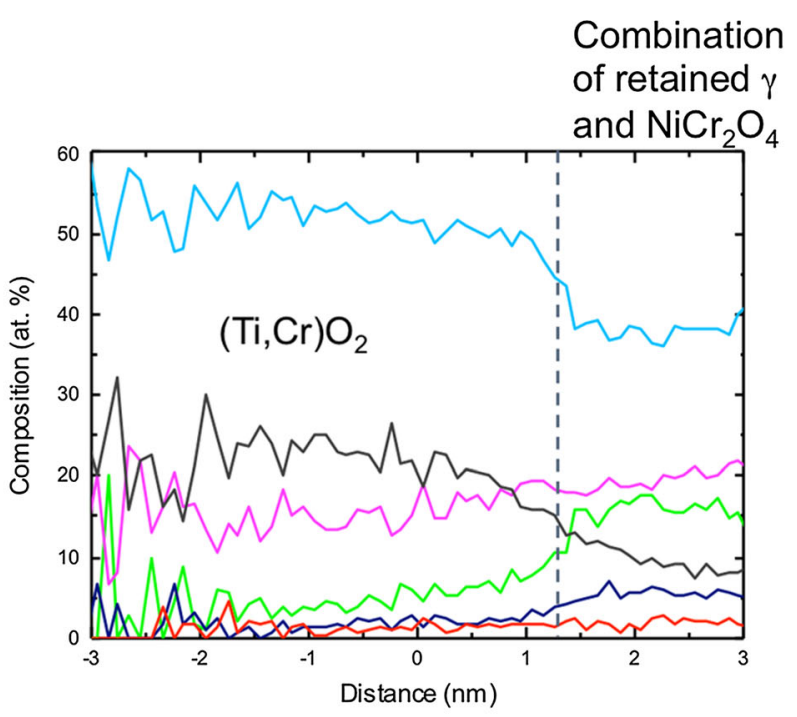

(d)

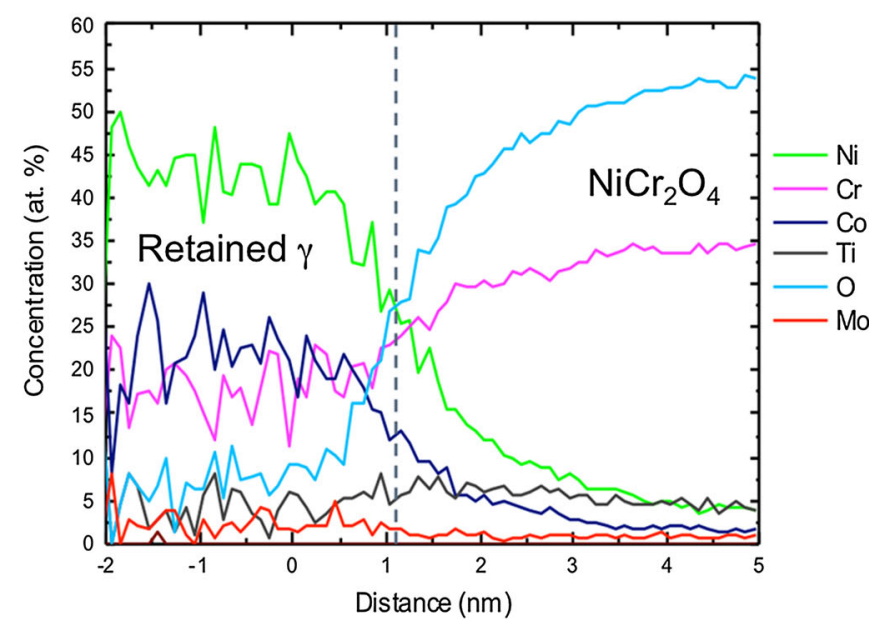

(f)

Fig. 8- (a) SEM micrograph showing the section of the cantilever containing oxide buildup and porosity within the crack tip, (b) the final sharp needle that was analyzed in the atom probe, $(c)$ reconstruction of the needle, and $(d)$ through $(f)$ proximity histograms going across the boundaries between the phases shown in the needle. 


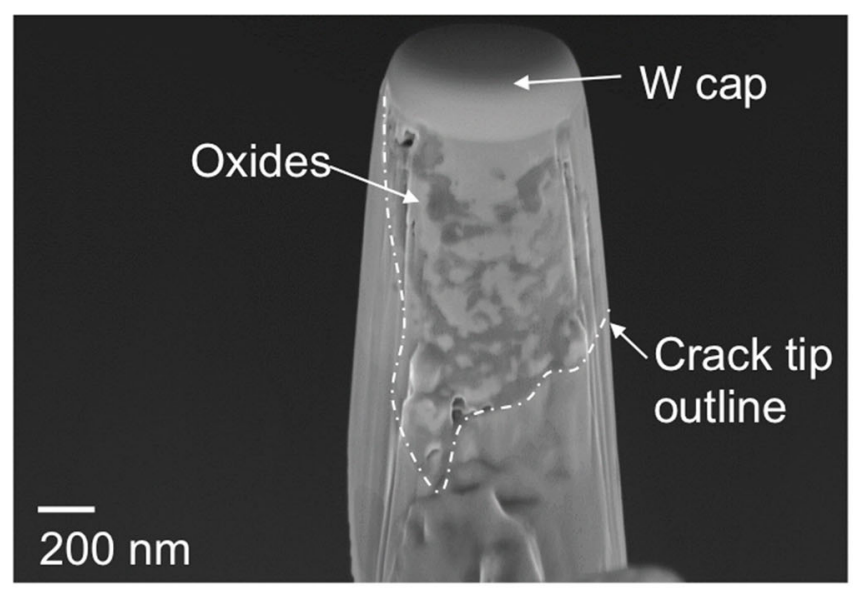

(a)

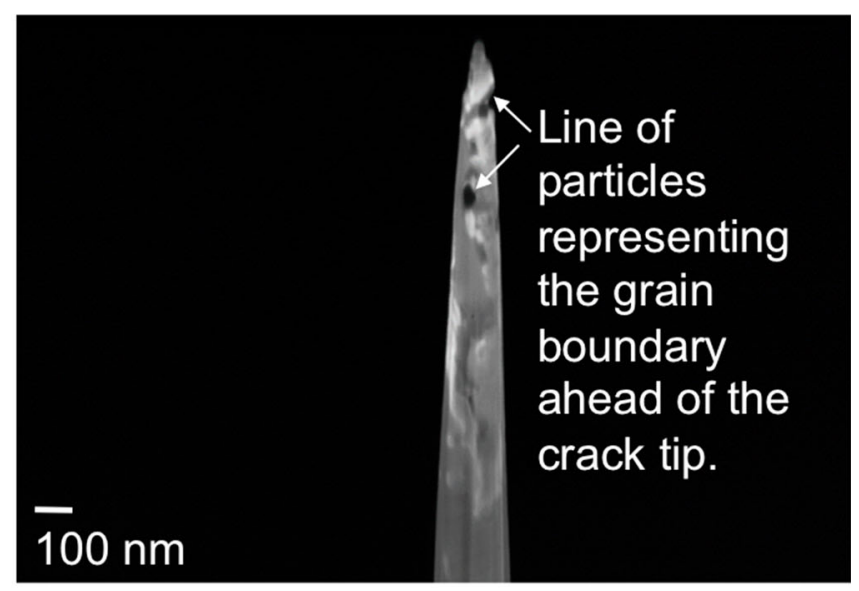

(b)
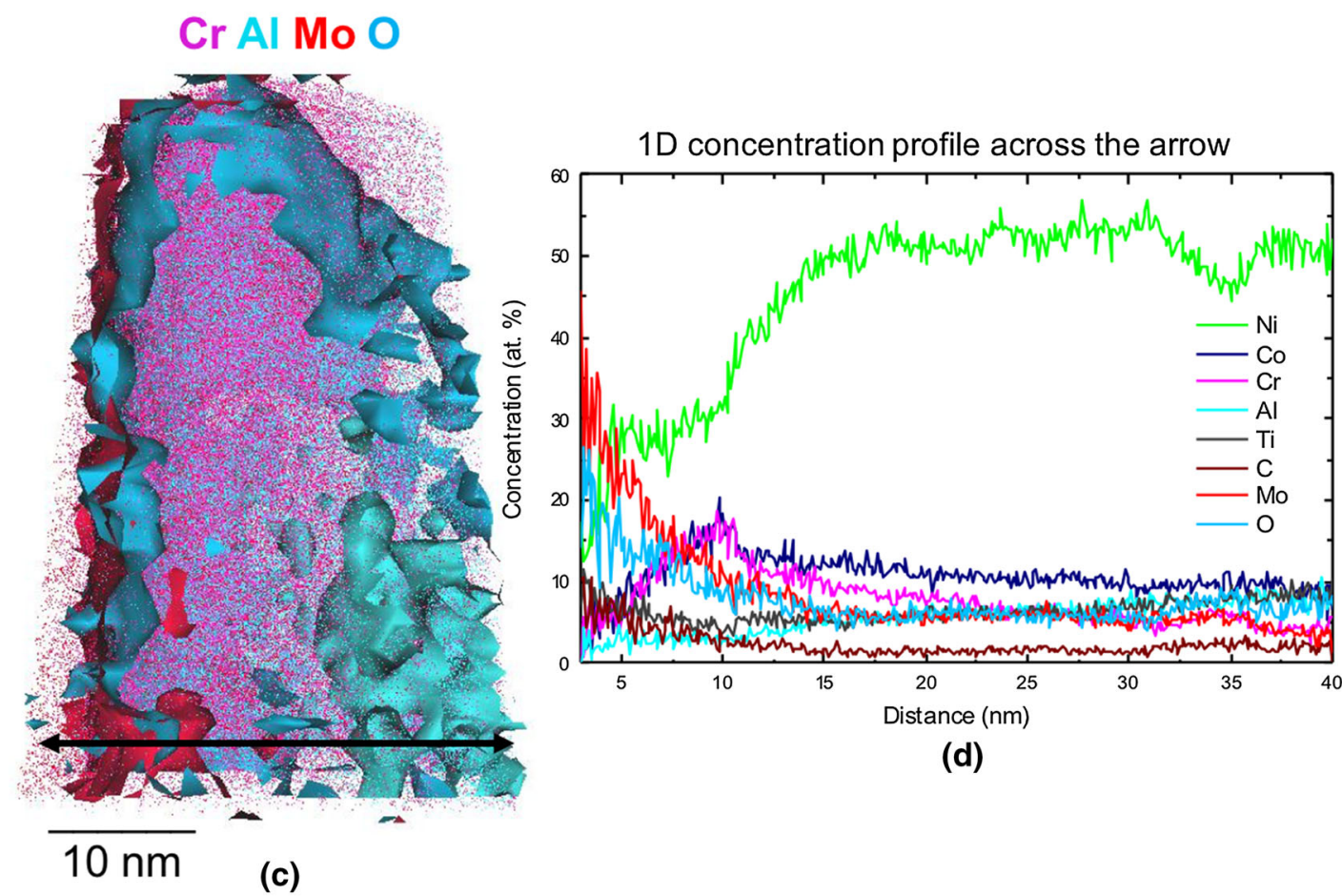

(d)

Fig. 9-Secondary electron micrographs showing $(a)$ the unsharpened sample and $(b)$ the sharp sample that was analyzed in the atom probe. $(c)$ Atom probe reconstruction and $(d)$ a proximity histogram across the arrow shown in (c).
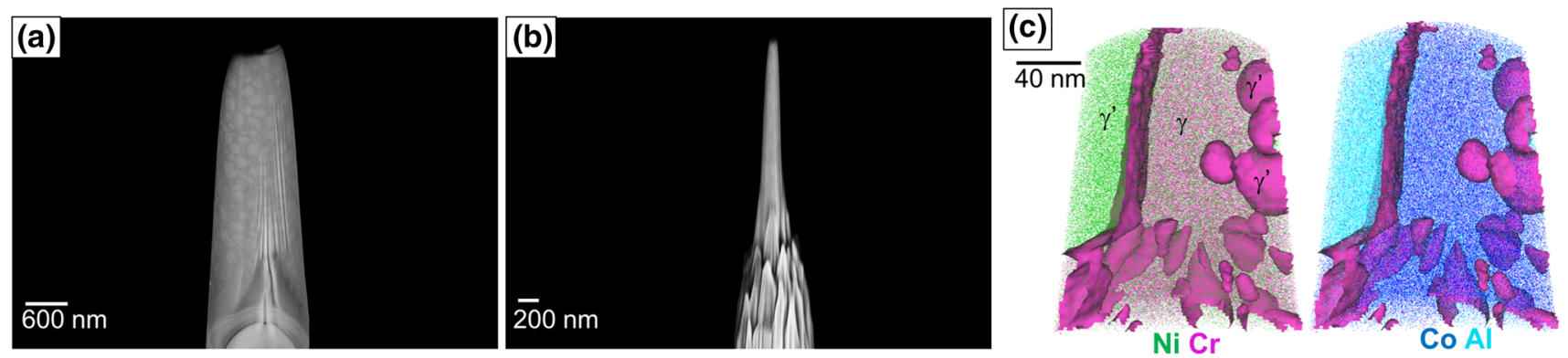

Fig. 10 - (a) and (b) Final stages of sample preparation and sharpening of the atom probe needle 3. (c) Reconstruction showing secondary and tertiary $\gamma^{\prime}$ from this sample. Elemental concentration maps are shown with isoconcentration surfaces at 12 at. pct $\mathrm{Cr}$. 
Table III. Elemental Composition of the $\gamma$ and $\gamma^{\prime}$ Phases (Secondary and Tertiary) in Atomic Percent Obtained from the Atom Probe Reconstruction Shown in Fig. 10(c)

\begin{tabular}{lllc}
\hline Element & $\gamma$ & Secondary $\gamma^{\prime}$ & Tertiary $\gamma^{\prime}$ \\
\hline $\mathrm{Ni}$ & 34.8 & 67.5 & 66.1 \\
$\mathrm{Cr}$ & 29.6 & 2.2 & 2.9 \\
$\mathrm{Al}$ & 1.2 & 12 & 13.4 \\
$\mathrm{Co}$ & 28.3 & 6.8 & 7.3 \\
$\mathrm{Ti}$ & 0.2 & 8.2 & 7.2 \\
$\mathrm{Mo}$ & 5 & 1.9 & 2.1 \\
$\mathrm{Zr}$ & 0.02 & 0.02 & 0.02 \\
$\mathrm{Hf}$ & 0.02 & 0.1 & 0.1 \\
$\mathrm{Ta}$ & 0.03 & 1.2 & 0.8 \\
$\mathrm{C}$ & 0.1 & 0.1 & 0.02 \\
$\mathrm{~B}$ & 0.02 & 0.02 & 0.05 \\
\hline
\end{tabular}

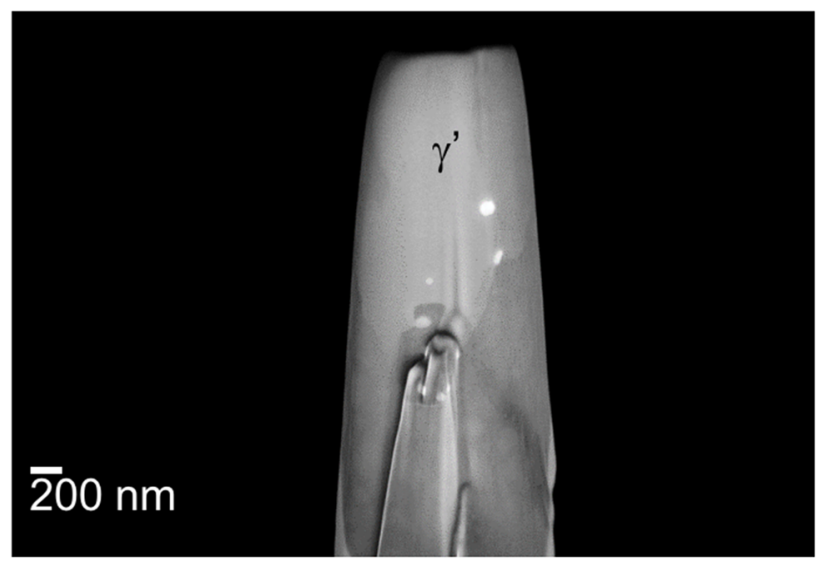

(a) and nanoparticles of hafnia that surround the crack. However, Figure 13(c) shows the very tip of the crack. At this stage, only a discontinuous layer of alumina is present.

\section{DISCUSSION}

\section{A. Comparing Surface and Crack Tip Behavior}

Thermally grown surface oxide formation on the nickel-based turbine disc alloy RR 1000 was the subject of a number of previous studies. ${ }^{[7,16-18]}$ In one such study, performed using TGA, SEM-EDX, and X-ray diffraction, the oxide scale formed on the RR1000 alloy was assessed after air exposures up to 5000 hours at $800{ }^{\circ} \mathrm{C}^{[19]}$ The surface oxide was reported to comprise a layer of chromia, with rutile forming on its outer surface

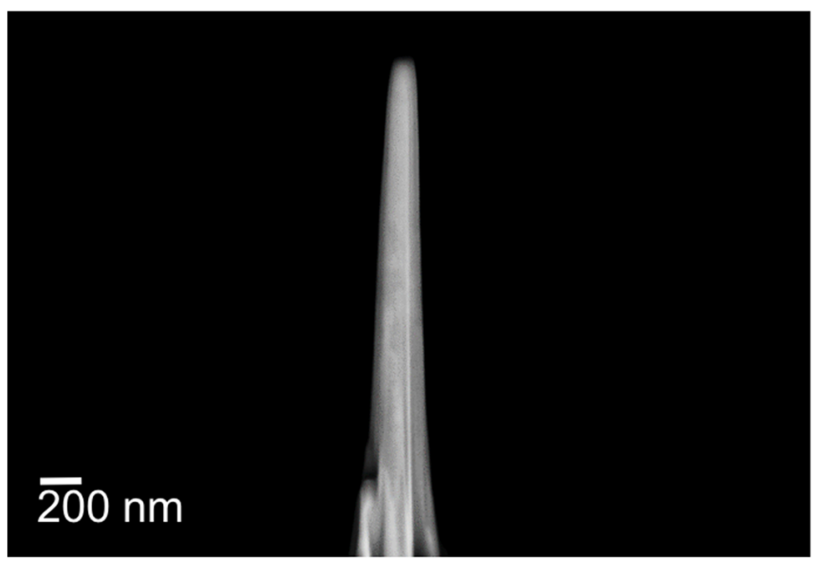

(b)

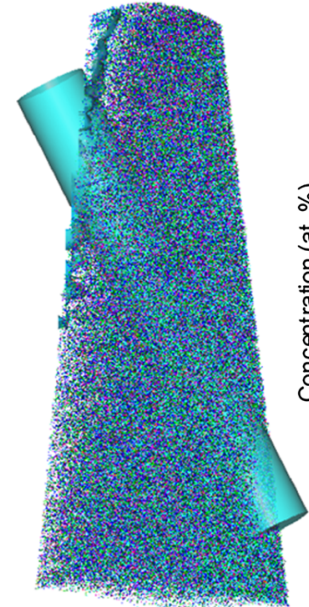

(c)

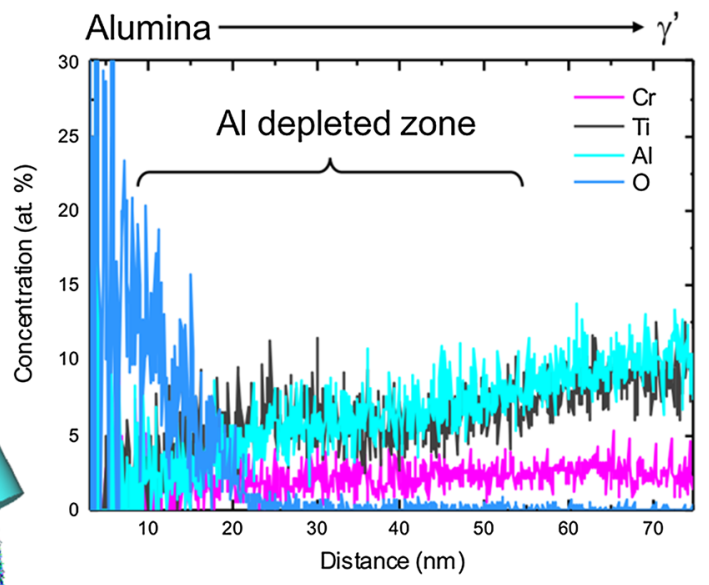

(d)

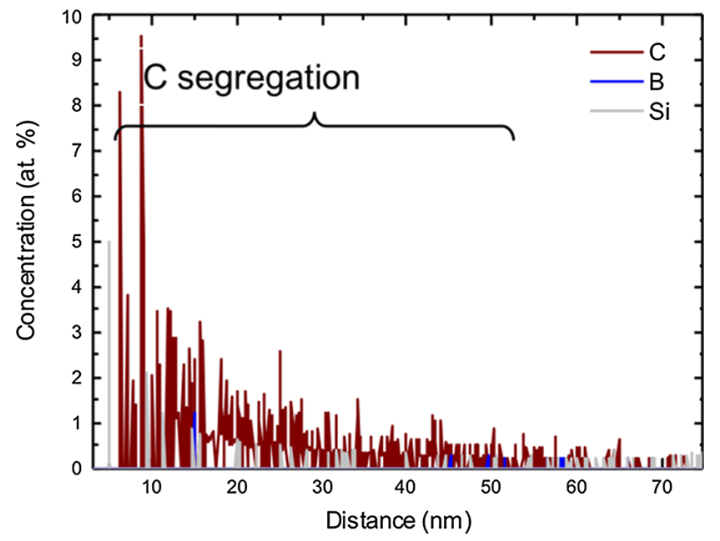

Fig. 11- (a) and (b) SEM micrographs of the samples during sharpening, showing a $\gamma^{\prime}$ particle in the tip of the needle, with a part of the oxide-metal interface close to the tip. (c) Atom probe reconstruction taken from the external alumina envelope surrounding the secondary crack tip. (d) 1-D concentration profiles showing the segregation and partitioning preference of various elements, including $\mathrm{Si}$, C, and $\mathrm{O}$, obtained from the cylindrical volume identified in (c). 

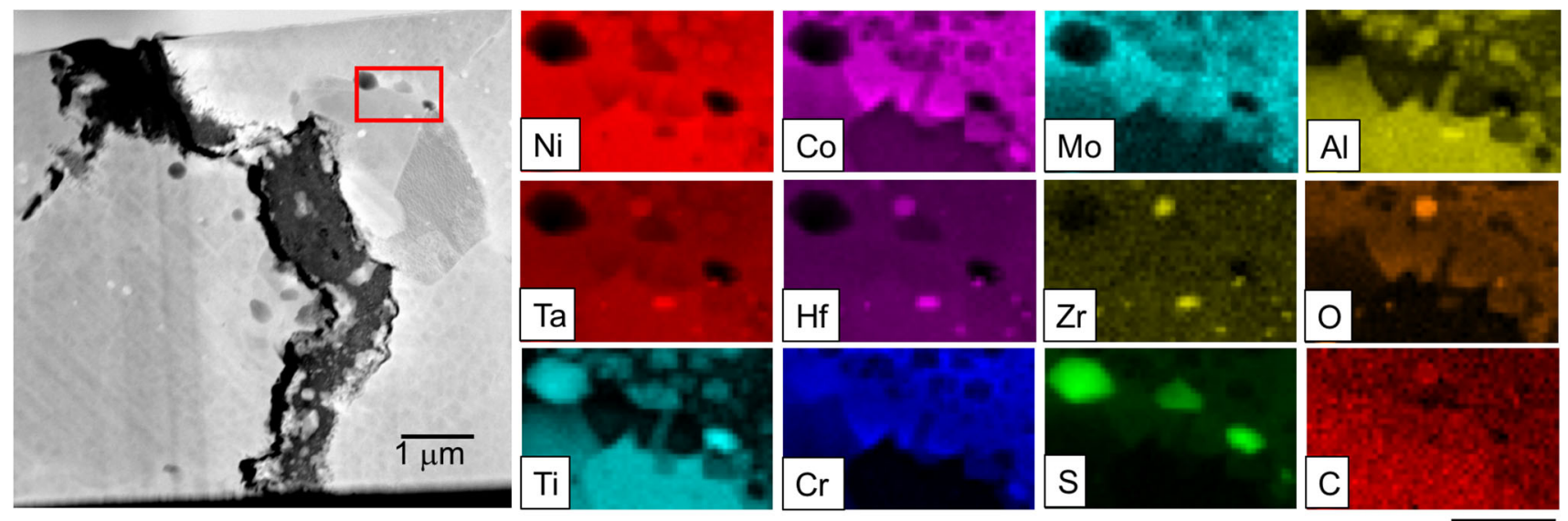

$500 \mathrm{~nm}$

Fig. 12-TEM micrograph of the crack and surrounding particles and STEM-EDX elemental concentration maps taken from the region highlighted by the red box (Color figure online).

and internal oxidation of both aluminum and titanium. Preferential oxidation of selected elements occurs based on the oxygen partial pressure achieved locally. The crack tips studied in the present work exhibit similar behavior, with the oxygen partial pressure being lower further within the crack and, in the present case, forming a chromia-based oxide surrounded by a continuous layer of alumina, as shown in Figure 6. The oxygen gradient measured at the grain boundary ahead of the oxide (Figure 9) also provides a strong indicator that the embrittling effect of oxygen extends further than oxide formation. It is worth noting that no sulfur was detected at the alumina-metal interface analyzed in Figure 9.

Previous studies analyzing combined sulfur-oxygen exposures report lower damage rates than sulfur exposure alone, suggesting that preferential oxidation delays sulfur corrosion. ${ }^{[2]}$ Further studies into this mechanism hypothesize surface oxide formation, followed by sulfur diffusion along the grain boundaries within the oxide. Sulfur would diffuse to the oxide-metal interface, then cause the preferential sulfidation of specific elements that subsequently grow outward toward the surface along the grain boundaries within the oxide. ${ }^{[20]}$ The diffusion of sulfur to the oxide-metal interface was documented in the case of surface oxide scales, ${ }^{[21,22]}$ encouraging spallation and causing material loss at an accelerated rate. ${ }^{[23]}$ This behavior was not observed at crack tips under the current testing conditions, as proved by the atomic resolution microstructural characterization shown in Figure 11.

Other studies reported the formation of stable $\mathrm{Cr}$ - $\mathrm{Ti}$ sulfides in the denuded zone beneath a surface oxide scale. ${ }^{[24,25]}$ A finding subsequently confirmed by Chang et al. ${ }^{[26]}$ who corroded their alloy for 80 hours in a sulfur and oxygen containing environment, and which is consistent with our current work, shown in Figures 5 and 11. The formation of chromium sulfides is considered undesirable, as the sulfidation rate of chromium is four to five orders of magnitude faster than the corresponding oxidation rate, preventing the formation of a protective scale. ${ }^{[27]}$ Our work supports their hypothesis, as sulfur was not found as elemental segregation at the oxide-metal interface in the case of samples extracted from the crack tip.

However, a study performed by Floreen and Kane ${ }^{[2]}$ concluded that, in many cases, the material's response was different under static exposures and applied stress. They noted that some environments that increased crack growth rates under fatigue loading did not always produce a significant general attack on the material in the unstressed condition. The implication of their work is that static hot corrosion tests will not be able to reliably assess environmental sensitivity of an alloy under applied stress. As such, crack tips and surfaces are not comparable and different environmental exposures during mechanical tests are necessary.

\section{B. Effect of Corrosion on Crack Tip Propagation}

The fracture surfaces shown in Figure 3 reveal that the addition of $300 \mathrm{ppm}$ of $\mathrm{SO}_{x}$ to the testing atmosphere was sufficient to alter the crack propagation behavior in RR1000 under dwell fatigue conditions at $700{ }^{\circ} \mathrm{C}$ when compared to air exposure alone. Fracture of the prenotched samples occurred at 90 deg from the tensile axis and, ultimately, failure occurred intergranularly in a uniaxial tensile mode for all samples. Intergranular fracture was expected to be the main failure mode based on a study published by $\mathrm{Li}$ et al..$^{[13]}$ on the same RR1000 alloy, though their samples were studied following a supersolvus heat treatment, which created a coarse-grained microstructure. Their study analyzed samples that had been subjected to different cooling rates after heat treatments and found that dwell fatigue crack propagation behavior was sensitive to the distribution of $\gamma^{\prime}$ precipitates (mainly tertiary). Their study also found that, at $700{ }^{\circ} \mathrm{C}$, grain boundary embrittlement was the main mechanism responsible for accelerated failure when samples were exposed to air rather than kept under vacuum. The present results allow us the opportunity to extend their argument to sulfur exposure and to shed insight into grain boundary oxidation and sulfidation ahead of the crack tip. 

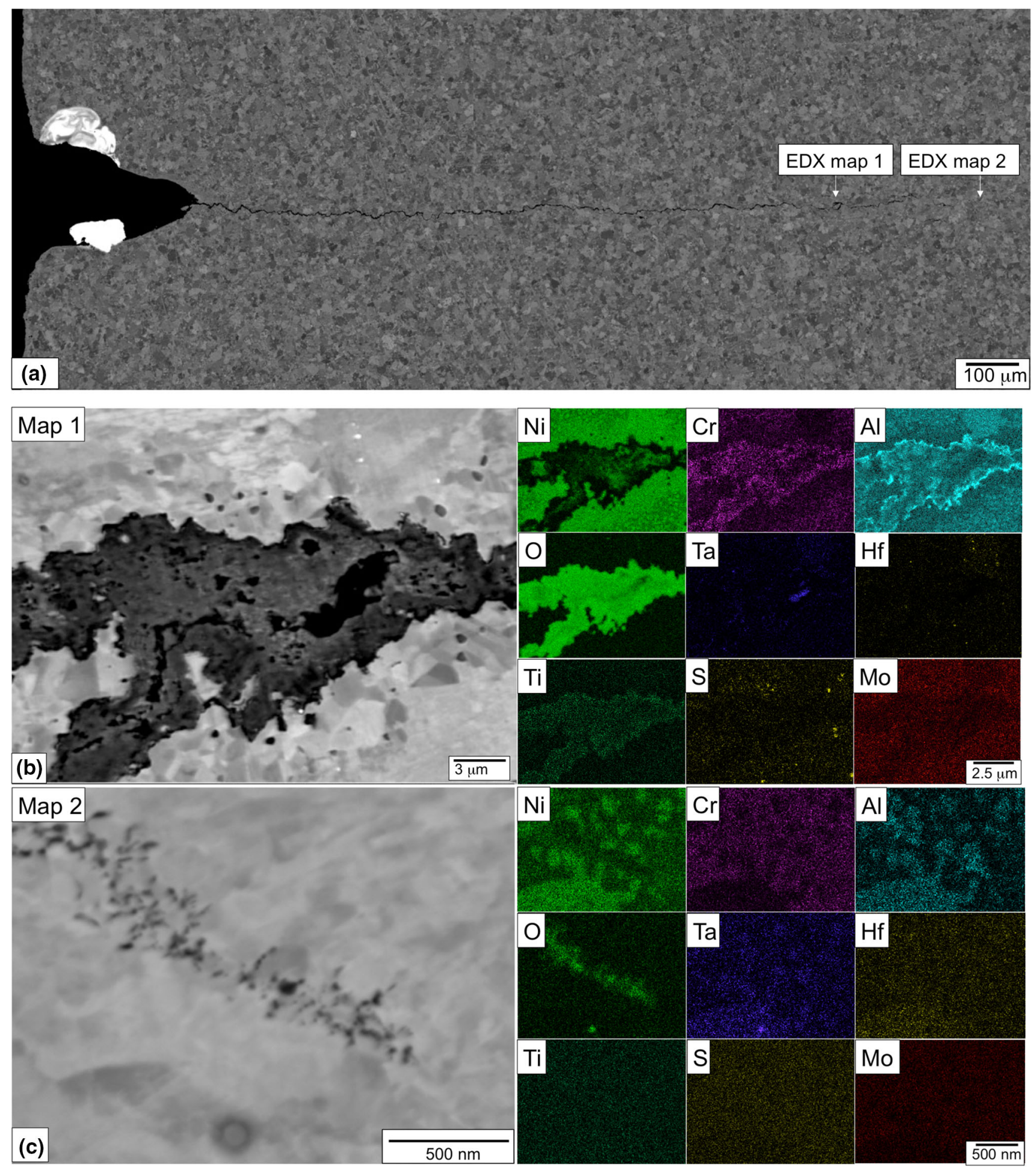

Fig. 13- (a) Backscattered electron micrograph showing the entire crack and the locations from which the EDX maps were acquired. (b) Micrograph showing, in detail, an oxidized portion of the crack and associated EDX compositional maps. (c) Micrograph showing the tip of the crack and EDX elemental composition maps.

Floreen and Kane's study ${ }^{[2]}$ analyzed crack tip propagation speeds during fatigue experiments at $650{ }^{\circ} \mathrm{C}$ in either an air (oxidative) +5 pct $\mathrm{SO}_{2}$ atmosphere or a helium (inert) +5 pct $\mathrm{SO}_{2}$ atmosphere. They demonstrated that at lower stress intensity ranges, the crack propagation rate was delayed in air compared with an inert atmosphere. They speculated that the mitigating effect of air could be due to oxidation inhibiting sulfide formation. The effect of air exposure on time-dependent cracking in nickel-based superalloys was reviewed by Woodford ${ }^{[28]}$ who discussed three possible interactions: adsorption of oxygen at the crack tip, formation of 
oxides at the crack tip, or formation of subsurface oxides at grain boundaries ahead of the crack tip. Woodford, after reviewing the evidence, concluded that intergranular oxygen penetration leads to embrittlement, though only if a reaction occurs (elemental oxygen does not have an embrittling effect on pure nickel). Exposure to corrosive agents, such as sulfur and chlorine, between $450{ }^{\circ} \mathrm{C}$ and $-900{ }^{\circ} \mathrm{C}$ was shown to embrittle nickel more severely than oxygen alone.

\section{Effect of Chromium and Titanium}

Figure 8 shows the chromia and other oxides that are present at the crack tip. The lack of $\mathrm{Ti}$ in solid solution in the chromia is noteworthy because current oxidation theories speculate that $\mathrm{Ti}$ increases the oxidation rate by dissolving in the chromia scale in the form of $\mathrm{Ti}^{4+}$ ions, which substitute for $\mathrm{Cr}^{3+}$; therefore, more vacancies are required to keep charge neutrality, which makes diffusion faster. ${ }^{[16]}$ Kitaguchi et al. ${ }^{[15]}$ performed an atom probe analysis on an oxidized RR1000 dwell fatigue crack tip that was not exposed to sulfur. They saw $\sim 5$ at. pet Ti in solid solution in the chromia of an oxidized crack tip in RR1000, as well as rutile particles similar to those identified in Figure 8. The main difference between both samples is the sulfur exposure. Therefore, this result is a likely indicator that the sulfur diffuses ahead of the oxide front and forms Ti-Cr sulfides. The titanium forms sulfides and the local reduction of titanium is evident, as it does not form a solid solution in the chromia. As the crack propagates, the sulfides then oxidize, releasing the sulfur and creating the $(\mathrm{Ti}, \mathrm{Cr}) \mathrm{O}_{2}$ particles we detected. The oxidation of sulfides releasing elemental sulfur on grain boundaries and causing embrittlement was previously shown as a potential mechanism of gas-phase embrittlement, ${ }^{[29]}$ although based on our observations, the sulfur diffuses ahead of the advancing crack front to form more sulfides under the current testing conditions.

\section{Effect of Refractory Elements}

In the present study, $\mathrm{Ta}, \mathrm{Zr}$, and $\mathrm{Hf}$ oxidized, forming oxide particles at grain boundaries ahead of the crack tips, as shown in Figure 12. Therefore, these elements have no influence on the sulfur resistance of the alloy. MC carbides in nickel superalloy RR1000 are generally found to be $\mathrm{Ta}$ and $\mathrm{Ti}$ rich. It is possible that the presence of $\mathrm{S}$ could have removed Ti from MC carbides, though further studies are needed to confirm this.

Besides high chromium levels, low-level additions of grain boundary segregating elements, such as $\mathrm{Hf}$ and $\mathrm{Zr}$, have previously been reported as being beneficial in reducing oxygen embrittlement in nickel superalloys. ${ }^{[28]}$ $\mathrm{Hf}$ and $\mathrm{Zr}$, in particular, were reported to act as $\mathrm{S}$ getters. ${ }^{[28]}$ The oxidation of grain boundary sulfides has also been speculated to cause elemental sulfur embrittlement, resulting in local grain boundary decohesion under applied stress. ${ }^{[28]}$ Several previous studies on the additions of refractory metals, including Mo, W, Ta, and $\mathrm{Nb}$, to improve corrosion resistance were performed. ${ }^{[30,31]}$ Critically, the sulfidation rates measured for these metals were similar to the rate of oxidation of chromium in nickel superalloys. ${ }^{[30]}$ Ellingham diagrams showing the free energy and partial pressures required for the formation of metallic sulfides show that the most stable is tantalum sulfide $\mathrm{TaS}_{2}$, closely followed by $\mathrm{Hf}_{3} \mathrm{~S}_{2} \cdot{ }^{[32]}$

\section{E. Comparing the Primary and Secondary Crack Tips}

Comparing Figures 6 and 13, it is clear that secondary crack tips can be analyzed to obtain information about the crack propagation mechanisms, but only if they are carefully selected from specific locations where the mechanisms are active. It is likely that, in the present tests, the crack propagation mechanism was initially driven by the presence of sulfur but switched from being sulfur driven to being oxygen driven, in this case after the crack length exceeded $\sim 1.5 \mathrm{~mm}$. It is clear that further work is required to characterize in-depth primary crack tips of tests that are interrupted at various stages in order to fully rationalize the fracture mechanisms.

\section{SUMMARY AND CONCLUSIONS}

This study presents detailed, high-resolution characterization of samples of the polycrystalline disc alloy RR1000 before and after environmental exposures under applied stress to analyze the embrittling effect of air and sulfur. The following conclusions can be drawn.

1. Exposure of samples to $300 \mathrm{ppm} \mathrm{SO}_{x}$ atmosphere during dwell fatigue at $700{ }^{\circ} \mathrm{C}$ substantially accelerated crack growth and failure when compared to air exposure alone.

2. Exposure to a saturated 98 pct $\mathrm{Na}_{2} \mathrm{SO}_{4}-2$ pct $\mathrm{NaCl}$ solution caused faster crack growth than air exposure. The salt-exposed sample showed extensive evidence of intergranular internal cracking.

3. Cracks were oxidized, containing a combination of $\mathrm{NiCr}_{2} \mathrm{O}_{4}$ spinel, followed by $(\mathrm{Ti}, \mathrm{Cr}) \mathrm{O}_{2}$ and $\mathrm{Al}_{2} \mathrm{O}_{3}$.

4. Sulfur was shown to form particles at grain boundaries ahead of and around the crack tips, weakening them and causing extensive internal cracking in the salted sample. These particles were ( $\mathrm{Ti}, \mathrm{Cr}$ ) sulfides, disproving the previous theories that Ta-rich $\mathrm{MC}$ carbides evolve into $\mathrm{M}_{2} \mathrm{SC}$ sulfides.

5. Sulfides appeared to have oxidized during the advancement of the crack front, creating (Ti, $\mathrm{Cr}) \mathrm{O}_{2}$ oxide particles visible within the chromia scale.

6. Hafnium and zirconium were detected as oxide particles around the crack tips, indicating that, in the present work, they did not act as sulfur scavengers. 


\section{ACKNOWLEDGMENTS}

Materials for the present work were supplied by Rolls-Royce plc. Funding is acknowledged under the Rolls-Royce-EPSRC Strategic Partnership Grant No. EPM005607/1. The authors also thank Professor Chris Grovenor for allowing access to the Cameca NanoSIMS 40 and Professor Peter Bruce for allowing access to the Zeiss Merlin SEM-EDX, both located in the Department of Materials, University of Oxford.

\section{OPEN ACCESS}

This article is distributed under the terms of the Creative Commons Attribution 4.0 International License (http://creativecommons.org/licenses/by/4.0/), which permits unrestricted use, distribution, and reproduction in any medium, provided you give appropriate credit to the original author(s) and the source, provide a link to the Creative Commons license, and indicate if changes were made.

\section{REFERENCES}

1. K. Chen, L.R. Zhao, and J.S. Tse: Acta Mater., 2003, vol. 51 (4), pp. 1079-86.

2. S. Floreen and R.H. Kane: Metall. Trans. A, 1979, vol. 10A, pp. $1745-51$.

3. J.J. Moverare, G. Leijon, H. Brodin, and F. Palmert: Mater. Sci. Eng. A, 2013, vol. 564, pp. 107-15.

4. R.A. Rapp: Corros. Sci., 2002, vol. 44 (2), pp. 209-21.

5. D.J. Child, J. Meldrum, and P. Onwuarolu: Mater. Sci. Technol. (United Kingdom), 2017, vol. 33 (9), pp. 1040-47.

6. H.L. Cockings, K.M. Perkins, and M. Dowd: Mater. Sci. Technol. (United Kingdom), 2017, vol. 33 (9), pp. 1048-55.

7. A. Encinas-Oropesa, N.J. Simms, J.R. Nicholls, G.L. Drew, J. Leggett, and M.C. Hardy: Mater. High Temp., 2009, vol. 26(3), pp. 241-49.

8. Y.-R. Zheng, Y.-L. Cai, Z.-C. Ruan, and S.-W. Ma: J. Aeronaut. Mater., 2006, vol. 26 (3), pp. 25-34.

9. C.L. White, J.H. Schneibel, and R.A. Padgett: Metall. Trans. A, 1983, vol. 14A, pp. 595-610.
10. P.A.J. Bagot, O.B.W. Silk, J.O. Douglas, S. Pedrazzini, D.J. Crudden, T.L. Martin, M.C. Hardy, M.P. Moody, and R.C. Reed: Acta Mater., 2017, vol. 125, pp. 156-65.

11. P. Kontis, H.A.M. Yusof, S. Pedrazzini, M. Danaie, K.L. Moore, P.A.J. Bagot, M.P. Moody, C.R.M. Grovenor, and R.C. Reed: Acta Mater., 2016, vol. 103, pp. 688-99.

12. P. Kontis, A. Alabort, D. Barba, D.M. Collins, A.J. Wilkinson, and R.C. Reed: Acta Mater., 2017, vol. 124, pp. 498-500.

13. H.Y. Li, J.F. Sun, M.C. Hardy, H.E. Evans, S.J. Williams, T.J.A. Doel, and P. Bowen: Acta Mater., 2015, vol. 90, pp. 355-69.

14. S. Pedrazzini, D.J. Child, G. West, S.S. Doak, M.C. Hardy, M.P. Moody, and P.A.J. Bagot: Scripta Mater., 2016, vol. 113, pp. $51-54$

15. H.S. Kitaguchi, M.P. Moody, H.Y. Li, H.E. Evans, M.C. Hardy, and S. Lozano-Perez: Scripta Mater., 2015, vol. 97, pp. 41-44.

16. S. Cruchley, M.P. Taylor, H.E. Evans, M.C. Hardy, and D.J. Child: Mater. Sci. Technol. (United Kingdom), 2014, vol. 30(15), pp. $1884-89$.

17. M.P. Taylor, H.E. Evans, S. Stekovic, and M.C. Hardy: Mater. High Temp., 2012, vol. 29(2), pp. 465-75.

18. A. Encinas-Oropesa, G.L. Drew, M.C. Hardy, A.J. Leggett, J.R. Nicholls, and N.J. Simms: Proc. Int. Symp. on Superalloys, 2008.

19. S. Cruchley, H.E. Evans, M.P. Taylor, M.C. Hardy, and S. Stekovic: Corros. Sci., 2013, vol. 75, pp. 242-52.

20. S. Mrowec: Oxid. Met., 1995, vol. 44 (1), pp. 177-209.

21. S. Pahlavanyali, H.T. Pang, F. Li, S. Bagnall, and C. Rae: Mater. Sci. Technol. (United Kingdom), 2014, vol. 30(15).

22. Y. Chen, R.C. Reed, and E.A. Marquis: Scripta Mater., 2012, vol. 67 (9), pp. 779-82.

23. D. Deb, S. Ramakrishna Iyer, and V.M. Radhakrishnan: Mater. Lett., 1996, vol. 29(1-3), pp. 19-23.

24. Y. Murata, R. Hashizume, A. Yoshinari, N. Aoki, M. Morinaga, and Y. Fukui: Proc. Int. Symp. Superalloys, 2000, pp. 285-94.

25. R. Bürgel, J. Grossmann, O. Lüsebrink, H. Mughrabi, F. Pyczak, R.F.F. Singer, A. Volek, R. Burgel, J. Grossmann, O. Lusebrink, H. Mughrabi, F. Pyczak, R.F.F. Singer, and A. Volek: Proc. Int. Symp. Superalloys, 2004, vol. 200, p. 25.

26. J.X. Chang, D. Wang, T. Liu, G. Zhang, L.H. Lou, and J. Zhang: Corros. Sci., 2015, vol. 98, pp. 585-91.

27. D.J. Young: Elsevier Corros. Ser., 2008, vol. 1, p. 242.

28. D.A. Woodford: Energy Mater. Mater. Sci. Eng. Energy Syst., 2006, vol. 1 (1), pp. 59-79.

29. R.H. Bricknell, R.A. Mulford, and D.A. Woodford: Metall. Trans. A, 1982, vol. 13A, pp. 1223-32.

30. S. Mrowec: Oxid. Met., 1995, vol. 44 (1), pp. 177-209.

31. J.X. Chang, D. Wang, T. Liu, G. Zhang, L.H. Lou, and J. Zhang: Corros. Sci., 2015, vol. 98, pp. 585-91.

32. S.R. Shatynski: Oxid. Met., 1977, vol. 11 (6), pp. 307-20. 